OPEN ACCESS

Edited by:

Carolina Henritta Pohl, University of the Free State,

South Africa

Reviewed by:

Ian A. Cleary,

Grand Valley State University,

United States

Derek Thomas,

Grand Valley State University,

United States

${ }^{*}$ Correspondence:

Patrick Van Dijck

patrick.vandijck@kuleuven.vib.be

Specialty section:

This article was submitted to Biofilms, a section of the journal

Frontiers in Cellular and

Infection Microbiology

Received: 01 November 2020

Accepted: 21 December 2020

Published: 02 February 2021

Citation:

Van Dyck K, Viela F, Mathelié-Guinlet M, Demuyser L, Hauben E, Jabra-Rizk MA, Vande Velde G, Dufrêne YF, Krom BP and

Van Dijck P (2021) Adhesion of

Staphylococcus aureus to

Candida albicans During

Co-Infection Promotes Bacterial

Dissemination Through the

Host Immune Response.

Front. Cell. Infect. Microbiol. 10:624839.

doi: 10.3389/fcimb.2020.624839

\section{Adhesion of Staphylococcus aureus to Candida albicans During Co-Infection Promotes Bacterial Dissemination Through the Host Immune Response}

\author{
Katrien Van Dyck ${ }^{1,2}$, Felipe Viela ${ }^{3}$, Marion Mathelié-Guinlet ${ }^{3}$, Liesbeth Demuyser $^{1,2}$, \\ Esther Hauben ${ }^{4}$, Mary Ann Jabra-Rizk ${ }^{5,6}$, Greetje Vande Velde ${ }^{7}, Y_{\text {ves F. Dufrêne }}^{3}$, \\ Bastiaan P. Krom ${ }^{8}$ and Patrick Van Dijck ${ }^{1,2 *}$ \\ ${ }^{1}$ Laboratory of Molecular Cell Biology, Institute of Botany and Microbiology, Department of Biology, KU Leuven, Leuven, \\ Belgium, 2 VIB Center for Microbiology, Leuven, Belgium, ${ }^{3}$ Louvain Institute of Biomolecular Science and Technology \\ (LIBST), UC Louvain, Louvain-la-Neuve, Belgium, ${ }^{4}$ Laboratory for Pathology, UZ Leuven and Department of Imaging and \\ Pathology, Translational Cell and Tissue Research, KU Leuven, Leuven, Belgium, ${ }^{5}$ Department of Oncology and Diagnostic \\ Sciences, Dental School, University of Maryland, Baltimore, Baltimore, MD, United States, ${ }^{6}$ Department of Microbiology and \\ Immunology, School of Medicine, University of Maryland, Baltimore, Baltimore, MD, United States, ${ }^{7}$ Biomedical MRI/ \\ MoSAIC, Department of Imaging and Pathology, KU Leuven, Leuven, Belgium, ${ }^{8}$ Department of Preventive Dentistry, \\ Academic Centre for Dentistry Amsterdam (ACTA), Vrije Universiteit Amsterdam and the University of Amsterdam, \\ Amsterdam, Netherlands
}

Interspecies interactions greatly influence the virulence, drug tolerance and ultimately the outcome of polymicrobial biofilm infections. A synergistic interaction is observed between the fungus Candida albicans and the bacterium Staphylococcus aureus. These species are both normal commensals of most healthy humans and co-exist in several niches of the host. However, under certain circumstances, they can cause hospital-acquired infections with high morbidity and mortality rates. Using a mouse model of oral co-infection, we previously showed that an oral infection with C. albicans predisposes to a secondary systemic infection with $S$. aureus. Here, we unraveled this intriguing mechanism of bacterial dissemination. Using static and dynamic adhesion assays in combination with single-cell force spectroscopy, we identified C. albicans Als1 and Als3 adhesins as the molecular players involved in the interaction with $S$. aureus and in subsequent bacterial dissemination. Remarkably, we identified the host immune response as a key element required for bacterial dissemination. We found that the level of immunosuppression of the host plays a critical yet paradoxical role in this process. In addition, secretion of candidalysin, the C. albicans peptide responsible for immune activation and cell damage, is required for $C$. albicans colonization and subsequent bacterial dissemination. The physical interaction with C. albicans enhances bacterial uptake by phagocytic immune cells, thereby enabling an opportunity to disseminate.

Keywords: Candida albicans, Staphylococcus aureus, oral candidiasis, polymicrobial, adhesins, immune response, candidalysin 


\section{INTRODUCTION}

The fungus C. albicans is a commensal organism of the oral cavity, skin, gastro-intestinal and urogenital tracts (Berman, 2012; Mayer et al., 2013). However, the use of corticosteroids can trigger its transition to a pathogen. C. albicans virulence factors include morphogenesis, adhesion, invasion and biofilm formation (Mukaremera et al., 2017). One of the key players in $C$. albicans biofilm formation is the Als3 protein (Zhao et al., 2004; Nobile et al., 2006), a member of the agglutinin-like sequence $(A L S)$ family which is only expressed during the hyphal or pseudo-hyphal phase (Hoyer et al., 2008; Hoyer and Cota, 2016). Another ALS family member, ALS1, shows $81 \%$ sequence homology to ALS3 and has overlapping functions but different expression patterns (Hoyer et al., 1998; Liu and Filler, 2011; Ho et al., 2019). Remarkably, a C. albicans ALS3 deletion strain is only impaired in biofilm formation in vitro but not in vivo, presumably due to the activation of additional adhesin genes, such as ALS1 (Nobile et al., 2006).

Within the host environment, fungi predominantly co-exist with diverse micro-organisms in complex communities (Shirtliff et al., 2009; Peters et al., 2012a; Lohse et al., 2018; Sultan et al., 2018). In the oral cavity, C. albicans is known to interact with other commensal bacterial species and is often co-isolated with other pathogens (Montelongo-Jauregui and Lopez-Ribot, 2018). $S$. aureus, a Gram-positive commensal bacterium, mainly colonizes the nares and skin but is considered a member of the oral microbial flora as well (McCormack et al., 2015; Thomer et al., 2016). S. aureus has a wide variety of virulence factors, yet it is not invasive and thus requires a portal of entry to cause systemic infections (van der Mee-Marquet et al., 2004; David and Daum, 2010; DeLeo et al., 2010; Kong et al., 2016). It is well established that C. albicans and S. aureus display a synergistic interaction with important clinical and therapeutic implications such as higher mortality rates (Carlson, 1982; Carlson, 1983; Peters and Noverr, 2013; Kong and Jabra-Rizk, 2015; Carolus et al., 2019). For the C. albicans ALS3 deletion strain, binding of $S$. aureus to the hyphae is reduced, indicating the importance of the Als3 protein in the interaction with $S$. aureus (Peters et al., 2012b).

Oropharyngeal candidiasis (OPC), primarily caused by $C$. albicans, is one of the most common fungal biofilm-like infections characterized by thick white patches on the tongue and inner cheeks (Fanning et al., 2012; Patil et al., 2015; Swidergall and Filler, 2017). The mouse model of OPC is an established model to study oral candidiasis due to the close similarity of the disease process and host immune response, to that in humans (Solis and Filler, 2012). The model was successfully adapted to study C. albicans-S. aureus interactions during oral co-infection (Kong et al., 2015; Schlecht et al., 2015; Vila et al., 2020). Using this model, we previously found that in contrast to animals only infected with $S$. aureus, those coinfected with $C$. albicans had a higher oral colonization of $S$. aureus and were susceptible to $S$. aureus systemic infection. Subsequent studies aiming to provide mechanistic insights into this phenomenon attributed a role for the C. albicans Als3 adhesin, since dissemination of $S$. aureus was reduced when co-infected with a C. albicans ALS3 deletion strain (Kong et al., 2015; Schlecht et al., 2015). In addition, the immune response appears to be altered by co-infections of C. albicans and S. aureus compared to the corresponding single species infections and could be involved in facilitating fungal-bacterial synergy (Peters and Noverr, 2013; Allison et al., 2019). Interestingly, candidalysin, a peptide encoded by C. albicans ECE1, was recently shown to be the main factor involved in mucosal immune activation, neutrophil recruitment and cell damage during C. albicans infection (Moyes et al., 2016; Naglik et al., 2019; Rogiers et al., 2019). Candidalysin is one of eight peptides which are produced after processing of Ecel by kexin. However, the role of this newly identified toxin in mediating interspecies interactions was not previously investigated.

In this study, we provide insights into the multifaceted and dynamic mechanisms leading to $S$. aureus dissemination during oral co-infection with $C$. albicans. We demonstrate that the interaction with C. albicans is essential for $S$. aureus to cause systemic disease and identified both Als3 and Als1 as important molecular players of this interaction. Furthermore, we found that the host immune response is a key factor required for bacterial dissemination. In this regard, we show that both the level of immunosuppression and secretion of the peptide toxin candidalysin play pivotal roles.

\section{MATERIALS AND METHODS}

\section{Strains and Growth Conditions}

C. albicans and S. aureus strains used in this study are listed in Table 1. Prior to every experiment, $C$. albicans strains were cultured overnight in liquid yeast extract-peptone-dextrose (YPD) medium at $30^{\circ} \mathrm{C}$ and $\mathrm{S}$. aureus in $0.6 \mathrm{x}$ tryptic soy broth (TSB) medium supplemented with $0.2 \%$ glucose at $37^{\circ} \mathrm{C}$. For GFP-expressing $S$. aureus, the media was supplemented with $2 \mu \mathrm{g} / \mathrm{ml}$ of tetracycline. J774 murine macrophages (ATCC TIB-67) were maintained in Dulbecco's modified Eagle's medium (DMEM) with $10 \%$ fetal bovine serum (FBS) and antibiotic/antimycotic solution (PSA; 100 $\mathrm{U} / \mathrm{ml}$ of penicillin, $100 \mu \mathrm{g} / \mathrm{ml}$ of streptomycin and $250 \mathrm{ng} / \mathrm{ml}$ of amphotericin B). For phagocytosis assays, $80 \%$ confluent

TABLE 1 | Strains used in this study.

\begin{tabular}{|c|c|c|}
\hline Strain name & Genotype & Reference \\
\hline \multicolumn{3}{|c|}{ C. albicans strains } \\
\hline SC5314 & Wild type, clinical isolate & (Gillum et al., 1984) \\
\hline als $1 \Delta / \Delta$ & 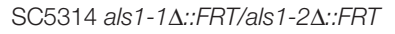 & This study \\
\hline als $3 \Delta / \Delta$ & SC5314 als3-1 $\Delta:: F R T / a l s 3-2 \Delta:: F R T$ & This study \\
\hline als1 als3 $\Delta \Delta / \Delta \Delta$ & $\begin{array}{l}\text { SC5314 als1-1 } 1:: F R T / a / s 1-2 \Delta:: F R T \\
\text { als3-1 }::: F R T / a / s 3-2 \Delta:: F R T\end{array}$ & This study \\
\hline $\operatorname{ece} 1 \Delta / \Delta$ & $\begin{array}{l}\text { SC5314 ece 1-1 } 1:: F R T / e c e 1-2 \Delta:: \\
\text { FRT }\end{array}$ & This study \\
\hline \multicolumn{3}{|c|}{ S. aureus strains } \\
\hline USA300 & Wild type, clinical isolate & $\begin{array}{l}\text { (Tenover and Goering, } \\
\text { 2009) }\end{array}$ \\
\hline USA300 - GFP & USA300 - pMV158 GFP & This study \\
\hline
\end{tabular}

For each of the deletion strains, three independent transformants were generated. 
macrophages were removed from culture flasks and 10-fold diluted in DMEM containing 10\% FBS. HeLa cells (ATCC CCL-2) were maintained in DMEM containing $4.5 \mathrm{~g} / \mathrm{l}$ glucose, supplemented with 1x GlutaMAX, 10\% FBS, and $50 \mu \mathrm{g} / \mathrm{ml}$ of gentamycin.

\section{Strain Construction}

The SAT-flipping strategy was used for the construction of the $C$. albicans deletion strains in the SC5314 background (Sasse and Morschhauser, 2012). Briefly, deletion cassettes were constructed by insertion of an upstream and downstream fragment of the target sequence (Supplementary Table 1) in the pSFS2 plasmid containing a nourseothricin resistance marker and a site-specific recombinase under a maltose inducible promotor. Plasmids were transformed in C. albicans to obtain deletion of the first allele and correct transformants were selected on YPD plates containing $200 \mu \mathrm{g} / \mathrm{ml}$ of nourseothricin. Correct transformants were grown in YP medium containing $2 \%$ maltose for excision of the cassette. A second round of transformation and excision was performed to delete the second allele (Sasse and Morschhauser, 2012). Three independent transformants were generated for each deletion strain. Deletion of the gene was checked using PCR. To verify that these deletions did not affect the growth, growth curves were made in YPD at $30^{\circ} \mathrm{C}$ and RPMI medium (RPMI 1640 medium with L-glutamine (Sigma) and buffered with $0.165 \mathrm{M}$ morpholinepropanesulfonic acid at $\mathrm{pH}$ 7) at $37^{\circ} \mathrm{C}$ by measuring the $\mathrm{OD}_{600 \mathrm{~nm}}$ over time. For the construction of the GFP-expressing $S$. aureus strain, plasmid pMV158-GFP containing optimized GFP under control of the MalP promotor (Nieto and Espinosa, 2003) was introduced into $S$. aureus USA300 by electroporation and transformants were selected on TSB plates containing $10 \mu \mathrm{g} / \mathrm{ml}$ of tetracycline ( $\mathrm{Li}$ et al., 2011).

\section{In vitro static C. albicans Adhesion and Biofilm Assay}

Biofilm and adhesion assays were performed in flat bottom 96well polystyrene plates. One day prior to the assay, plates were coated with $100 \mu \mathrm{l}$ of FBS and incubated overnight at $37^{\circ} \mathrm{C}$. Overnight $C$. albicans cultures were washed twice with phosphate buffered saline (PBS) and $1 \times 10^{6}$ C. albicans cells in $100 \mu \mathrm{l}$ RPMI were added to the wells. Plates were statically incubated for $90 \mathrm{~min}$ at $37^{\circ} \mathrm{C}$ to allow adhesion. For biofilm formation, wells were washed to remove non-adherent cells and supplemented with fresh RPMI medium after the $90 \mathrm{~min}$ adhesion period and further incubated for $24 \mathrm{~h}$. Afterwards, the medium was removed, wells were gently washed twice with PBS and resuspended in $200 \mu \mathrm{l}$ PBS. Wells were sonicated and plated on YPD plates in 10-fold dilutions for the enumeration of CFU.

\section{In Vitro Static Mixed Species Adhesion Assay}

Mixed species adhesion assays were performed in flat bottom 96well polystyrene plates. One day prior to the assay, plates were coated with $100 \mu \mathrm{l}$ of FBS and incubated overnight at $37^{\circ} \mathrm{C}$. Next, serum was removed and $1 \times 10^{6} \mathrm{C}$. albicans cells in $100 \mu \mathrm{l}$ RPI were added to the wells. Plates were statically incubated for $90 \mathrm{~min}$ at $37^{\circ} \mathrm{C}$ to allow adhesion and germ tube formation of the C. albicans cells. Afterwards, the supernatant was removed and $1 \times 10^{6} \mathrm{~S}$. aureus cells in $100 \mu \mathrm{l}$ RPMI were added to the wells. Plates were incubated at $37^{\circ} \mathrm{C}$ for $2 \mathrm{~h}$ to allow attachment of the bacterial cells to the $C$. albicans cells. Afterwards, the medium was removed, wells were gently washed twice with PBS and resuspended in $200 \mu \mathrm{l}$ PBS. Wells were sonicated, 10-fold dilutions were prepared and plated on TSB plates containing 8 $\mu \mathrm{g} / \mathrm{ml}$ of amphotericin B and YPD plates containing $10 \mu \mathrm{g} / \mathrm{ml}$ of vancomycin for the enumeration of $\mathrm{CFU}$ of $S$. aureus or $C$. albicans, respectively.

\section{In Vitro Dynamic Adhesion Assay Using a Bioflux System}

A Bioflux 1000Z setup (Fluxion Biosciences, USA) was used with an Axio Observer Zeiss Z1 automated microscope. All solutions were pre-warmed at $37^{\circ} \mathrm{C}$ before use to prevent air bubbles. PBS supplemented with $10 \% \mathrm{FBS}$ at $37^{\circ} \mathrm{C}$ was used to fill the channels of a 48-well microfluidics plate (Fluxion Biosciences, USA) from the inlet using a flow rate of $0.5 \mathrm{dyne} / \mathrm{cm}^{2}$ for $30 \mathrm{~min}$. Afterwards, an inoculum of $C$. albicans $3 \times 10^{6}$ cells $/ \mathrm{ml}$ of in PBS was added to the channel from the outlet well at a flow rate of $0.5 \mathrm{dyne} / \mathrm{cm}^{2}$ until the complete channel was filled with cells. Cells were allowed to adhere to the surface for $30 \mathrm{~min}$ without flow. Yeast-nitrogen-base media (YNB; supplemented with $0.5 \%$ glucose at $\mathrm{pH} 7$ ) was flowed from the inlet well at 0.5 dyne/ $\mathrm{cm}^{2}$ for $3 \mathrm{~h}$ to allow hyphae formation. Next, a GFP-expressing S. aureus inoculum of $1 \times 10^{7}$ cells $/ \mathrm{ml}$ in PBS was added at a flow rate of $0.5 \mathrm{dyne} / \mathrm{cm}^{2}$ from the inlet well. Images were taken every minute for $90 \mathrm{~min}$. C. albicans and S. aureus were visualized by imaging bright-field illumination and the GFP signal at $20 \mathrm{x}$ magnification on three randomly selected channel positions per condition. Images were analyzed using the ImageJ software (Schlecht et al., 2015).

\section{Single-Cell Force Spectroscopy}

$S$. aureus cells were grown overnight in TSB at $37^{\circ} \mathrm{C}, 150 \mathrm{rpm}$. The cells were harvested in the stationary phase and washed three times with PBS. C. albicans cells were incubated in RPMI medium to induce hyphae formation. Germinating C. albicans cells were immobilized on hydrophobic substrates. To prepare those substrates, glass coverslips coated with a thin layer of gold were immersed overnight in a $1 \mathrm{mM}$ solution of 1-dodecanethiol, rinsed with ethanol and dried under $\mathrm{N}_{2}$. After induction of germ tube formation, $200 \mu \mathrm{l}$ drops of the concentrated suspension were deposited on the hydrophobic substrates and let stand for $3 \mathrm{~h}$. The substrate was then rinsed to remove loosely attached cells and transferred to the AFM setup. For single-cell experiments, colloidal probes were prepared by attaching single silica microsphere $(6.1 \mu \mathrm{m}$ diameter, Bangs laboratories) with a thin layer of UV-curable glue (NOA 63, Norland Edmund Optics) on triangular shaped tip-less cantilevers (NP-O10, Bruker) using a Nanowizard IV AFM (JPK Instrument, Berlin, Germany). Cantilevers were then immersed for $1 \mathrm{~h}$ in Trisbuffered saline (Tris, $50 \mathrm{mM}$; NaCl, $150 \mathrm{mM}$; pH 8.5) containing 
$4 \mathrm{mg} / \mathrm{ml}$ of dopamine hydrochloride, rinsed in Tris-buffered saline, and used directly for cell probe preparation. In this end, $50 \mu \mathrm{l}$ of a 100 -fold diluted solution of $S$. aureus were transferred in a petri dish and the bacteria were let to settle for $15 \mathrm{~min}$. The nominal spring constant of the colloidal probe was determined by the thermal noise method. The colloidal probe was then mounted into the AFM and brought into contact with an isolated bacterium. The bacterial probe was positioned over an immobilized $C$. albicans germ tube on the hydrophobic surface. AFM measurements were performed at room temperature in PBS buffer using a Nanowizard 3 and Nanowizard 4 AFM (JPK Instrument, Berlin, Germany). Using the inverted optical microscope, the bacterial probe was approached toward a fungal cell. Force maps of 16x16 pixels were recorded on the germ tubes using a maximum applied force of $250 \mathrm{pN}$, and constant approach and retraction speeds of 1000 $\mathrm{nm} / \mathrm{s}$. For each condition, the interaction forces between at least 5 pairs of bacterial-fungal cells from independent cultures were measured. Histograms were generated by considering the force and the distance of the last rupture event for every curve.

\section{Mammalian Cell Damage Assay}

HeLa cells were seeded at $10^{4}$ cells/well in flat bottom tissue-culturetreated 96-well plates (Nunclon Delta Surface, Thermo Scientific). Cells were incubated for $24 \mathrm{~h}$ at $37^{\circ} \mathrm{C}$ and $5 \% \mathrm{CO}_{2}$. Overnight cultures of $C$. albicans were washed three times with PBS and added to the HeLa cells to a final concentration of $1 \times 10^{5}$ cells per well. Plates were incubated for $24 \mathrm{~h}$ at $37^{\circ} \mathrm{C}$ and $5 \% \mathrm{CO}_{2}$. The CyQUANT $^{\mathrm{TM}}$ LDH Cytotoxicity Assay Kit (Invitrogen) was used for read-out. Shortly, $50 \mu \mathrm{l}$ of the supernatant of all wells was transferred to a new flat bottom 96-well plate and $50 \mu \mathrm{l}$ of reaction mixture was added. Plates were incubated in the dark for $30 \mathrm{~min}$. Next, $50 \mu \mathrm{l}$ of stopping buffer was added and the absorbance was measured at 490 and $680 \mathrm{~nm}$. Positive and negative controls were included. The percentage of cytotoxicity compared to the positive control was calculated by subtracting the $680 \mathrm{~nm}$ values from the $490 \mathrm{~nm}$ values.

\section{In Vitro Phagocytosis Assay}

Tissue-culture-treated 12-well plates were seeded with $3 \times 10^{4}$ cells/ $\mathrm{ml}$ of $C$. albicans in YNB with $0.5 \%$ glucose $\mathrm{pH} 7$ and statically incubated for $3 \mathrm{~h}$ at $37^{\circ} \mathrm{C}$ to allow initial attachment and hyphae formation. Wells were washed once with PBS and $1 \times 10^{6}$ cells $/ \mathrm{ml}$ of GFP-expressing $S$. aureus were added. Plates were incubated for 90 min under gentle agitation at $37^{\circ} \mathrm{C}$ to allow bacterial attachment to the hyphae. Afterwards, wells were washed once with PBS and $1 \times 10^{5}$ cells $/ \mathrm{ml}$ of $\mathrm{J774}$ murine macrophages in DMEM supplemented with $10 \%$ FBS were added to the plates. Plates were immediately placed under the microscope to visualize phagocytosis. Images were taken every $2 \mathrm{~min}$ for $1 \mathrm{~h}$. Macrophages, C. albicans and $S$. aureus were visualized by imaging bright-field illumination and the GFP signal at 20x magnification on three randomly selected positions per condition. Images were analyzed using the ImageJ software (Scheres and Krom, 2016).

\section{In Vivo Oral Co-Infection Murine Model}

Eleven-week-old female C57BL/6J mice (Janvier) were used for all experiments. The model is based on Kong et al. (2015), with small modifications. To suppress the oral bacterial flora, mice received $0.5 \mathrm{mg} / \mathrm{ml}$ of ampicillin in their drinking water one week prior to the experiments. Mice were rendered susceptible to oral candidiasis by subcutaneous administration of cortisone acetate $(225 \mathrm{mg} / \mathrm{kg}$ body weight; low dosage) in the dorsum of the neck on day 1 and day 3 (or with $250 \mathrm{mg} / \mathrm{kg}$ body weight on day 1 , day 3 , and day 5 ; high dosage). To ensure that the total volume of $200 \mu \mathrm{l}$ cortisone was taken-up, mice were put asleep shortly with isoflurane to perform the injections and cortisone is vortexed well at all times (Solis and Filler, 2012). On the second day, mice were anesthetized by intraperitoneal injection of 50 $\mathrm{mg} / \mathrm{kg}$ of ketamine and $0.65 \mathrm{mg} / \mathrm{kg}$ of medetomidine. Animals were kept on $37^{\circ} \mathrm{C}$ heating pads and ophthalmic ointment was applied to avoid drying of the eyes. Animals were orally inoculated by placing calcium alginate swabs sublingually for $1 \mathrm{~h}$. These swabs were saturated for $10 \mathrm{~min}$ in a $C$. albicans suspension of $1 \times 10^{7}$ cells $/ \mathrm{ml}$ of in PBS. After infection, the anesthesia was reversed by an intraperitoneal injection of $0.5 \mathrm{mg} /$ $\mathrm{kg}$ atipamezole. On day 4 the same was done with $6 \times 10^{6}$ cells/ $\mathrm{ml}$ of $S$. aureus. In addition, $S$. aureus was added to the drinking water in the same concentration. Control groups infected with $C$. albicans or S. aureus alone were included in the study. Animals were weighted and monitored daily and sacrificed by cervical dislocation on day 7. Tissues were harvested, homogenized and plated for enumeration of CFU on bacterial and yeast chromogenic media (CHROMagar) for C. albicans and S. aureus.

\section{Whole Blood Analysis}

Mice blood samples were collected by cardiac puncture at the experimental endpoint and dipotassium ethylenediamine tetraacetic acid (EDTA) was used as an anticoagulant. Immediately after collection, whole blood samples were analyzed using the ADVIA 2120i hematology analyzer (Siemens) to assess different hematological parameters.

\section{Histology}

Tongues were fixed overnight in $4 \%$ paraformaldehyde, subsequently washed with PBS and further processed for histopathology. The sections were stained with Gram staining or PAS staining and examined with light microscopy.

\section{Statistical Analysis}

Three independent biological replicates were used in all experiments. The graphs display the average values and the standard error of the mean (SEM). The statistical method used is clarified in the figure legend: ${ }^{\star} \mathrm{P}<0.05 ;{ }^{* \star} \mathrm{P}<0.01 ;{ }^{\star * \star} \mathrm{P}<0.001$ and ${ }^{* * * *} \mathrm{P}<0.0001$.

\section{Ethics Statement}

All animal experiments were performed in accordance with the KU Leuven animal care guidelines and were approved by the Ethics Committee of the KU Leuven (project number P184/2017). 


\section{RESULTS}

\section{C. albicans Als1 and Als3 Adhesins Mediate the Interaction With S. aureus}

Previous studies showed that the C. albicans Als3 protein partially contributes to the interaction with S. aureus (Peters et al., 2012b). However, adherence of $S$. aureus to C. albicans hyphae still occurs to some extent when ALS3 is deleted. We hypothesize that this is likely due to other cell surface molecules, such as Als1. Therefore, we have constructed als $1 \Delta / \Delta$, als3 $\Delta / \Delta$ and als 1 als $\Delta \Delta / \Delta \Delta$ mutant strains in the C. albicans SC5314 background. In the remainder of the manuscript we will refer to them as als1, als 3 or als 1 als 3 mutants. No difference in growth was observed at $30^{\circ} \mathrm{C}$ and $37^{\circ} \mathrm{C}$ compared to the wild type strain (Supplementary Figure 1). As a control, adhesion and biofilm forming capacity of the different $C$. albicans strains was tested in the absence of bacteria in 96-well plates. C. albicans cells were statically incubated at $37^{\circ} \mathrm{C}$ for $90 \mathrm{~min}$ to allow adhesion, or for $24 \mathrm{~h}$ to allow biofilm formation. Only the als1 als3 mutant strain was impaired in adhesion (Supplementary Figure 2A) and both the C. albicans als 3 and als 1 als 3 strain were strongly impaired in biofilm formation compared to the wild type (Supplementary Figure 2B).

To verify whether Als1 plays an additional role in adhesion of $S$. aureus to C. albicans, a static in vitro mixed species adhesion assay was performed. Following $90 \mathrm{~min}$ of C. albicans adhesion, S. aureus cells were added to allow attachment of the bacterial cells. Results demonstrated no difference in adhesion of the C. albicans single deletion strains to the plastic surface, compared to the wild type strain. However, the adhesion ability of the C. albicans als1 als3 double mutant strain was significantly reduced by almost 25\% (Figure 1A). S. aureus adhered significantly less to the C. albicans als 3 and als 1 als 3 deletion strains while there was no significant difference in adhesion to the C. albicans als1 strain (Figure 1B). These results confirm that Als3 is important for the interaction with S. aureus. However, due to the inherently lower adhesion of the double deletion C. albicans strain to the plastic of the well plate, it is not feasible to conclude that deletion of ALS1 has an additional effect on S. aureus adhesion. Therefore, an in vitro dynamic adhesion assay using a Bioflux system was performed. C. albicans cells were introduced in the channel and allowed to adhere to the surface and form germ tubes and hyphae. Subsequently, GFP-expressing $S$. aureus cells were flowed through the channel and adhesion was imaged over time. From these images (Figure 1C) and the calculated mean fluorescence intensity (Supplementary Figure 3), we observed no difference in the ability of $S$. aureus to adhere to the hyphae of the C. albicans als1 strain compared to the wild type. Furthermore, we confirmed that the adhesion of S. aureus to the hyphae of the C. albicans als 3 strain was reduced, but not completely abolished. However, adhesion of $S$. aureus to the C. albicans als1 als3 strain was even further reduced, indicating a plausible additional role for Als1 in supporting the physical interaction with S. aureus.

\section{Deletion of ALS1 and ALS3 Reduces the Adhesion Force Between C. albicans and S. aureus}

To quantify bacterial-fungal adhesion forces, single-cell force spectroscopy (SCFS) was performed using a non-invasive protocol that ensures truly quantitative cell-cell interaction measurements (Beaussart et al., 2014; Xiao and Dufrene, 2016). A single bacterial cell was attached to a polydopamine-coated colloidal atomic force microscopy (AFM) probe and approached toward the germ tube of a fungal cell, immobilized on a hydrophobic substrate (Figure 2A, inset). This enabled us to quantify the adhesion forces between single bacterial and fungal cells. Force-distance curves recorded for S. aureus adhesion to $C$. albicans wild type germ tubes (Figure 2B, inset) featured adhesion events of $625 \mathrm{pN} \pm 286 \mathrm{pN}$ (mean + standard deviation (s.d.), $\mathrm{n}=541$ adhesive force curves from 3 cell pairs) (Figure 2A) and with rupture lengths of $300 \pm 91 \mathrm{~nm}$ (binding frequency $\sim 70 \%$ ) (Figure 2B). Similar data were obtained in 15 other cell pairs (Figure 2C). Adhesion forces did not substantially vary along the germ tubes, indicating their properties were homogeneous. Numerous force profiles featured sawtooth patterns with multiple force peaks of around $500 \mathrm{pN}$, which we attribute to the sequential unfolding of the tandem repeat domains of Als proteins in light of earlier force experiments. The $300 \mathrm{~nm}$ length is also consistent with the length of fully unfolded Als proteins (Beaussart et al., 2013).

To confirm that Als3 and Als1 adhesins indeed play a role in adhesion of $S$. aureus, we probed germ tubes from the C. albicans als 1 and als 3 single and double deletion strains. While the adhesion forces of the als 1 strain hardly changed compared to the wild type (adhesion events of $634 \mathrm{pN} \pm 273 \mathrm{pN}$ and rupture lengths of $339 \pm$ $94 \mathrm{~nm} ; \mathrm{n}=462$ adhesive force curves from 3 cell pairs) (Supplementary Figures 4A, B), the als3 strain (Supplementary Figure 4C) and the als1 als3 strain (Supplementary Figure 4D) showed a dramatic drop of adhesion force $(198 \mathrm{pN} \pm 147 \mathrm{pN} ; \mathrm{n}=85$ from 3 cell pairs; $198 \mathrm{pN} \pm 110 \mathrm{pN} \mathrm{n}=59$ from 3 cell pairs respectively). The average binding frequency was $10 \%$ for the als 3 strain and only $7 \%$ for the als 1 als 3 double mutant strain (Figure 2D). These results further support that both adhesins are required for adhesion of S. aureus, though Als3 is crucial for stable anchoring as there is no statistical difference between the als 3 and als 1 als3 strain.

\section{C. albicans Als1 and Als3 are Required for S. aureus Dissemination}

While previous experiments were conducted in vitro, expression of ALS1 might be more important in vivo. Since an ALS3 deletion strain is still able to form biofilms in vivo, it was proposed that Als1 compensates for the loss of Als3 in vivo (Nobile et al., 2006). Therefore, we tested these deletion strains in the oral co-infection murine model. In summary, mice are rendered susceptible to oral candidiasis by administration of cortisone acetate $(225 \mathrm{mg} / \mathrm{kg}$ body weight on day 1 and day 3 ). On the second day, animals are orally infected with C. albicans and two days later with S. aureus. Five days post $C$. albicans infection, organs were plated for enumeration of colony forming units (CFU) and tongue tissues were subjected to histopathology. Similar lesions on the tongues were observed for animals infected with the C. albicans wild type or the different deletions strains (Figure 3A). Microscopic analysis of tongue tissue sections stained by Periodic acid-Schiff (PAS) revealed C. albicans hyphal penetration of the superficial epithelial layer concomitant of an inflammatory response for both the wild type and als1 als 3 strain 
A

C

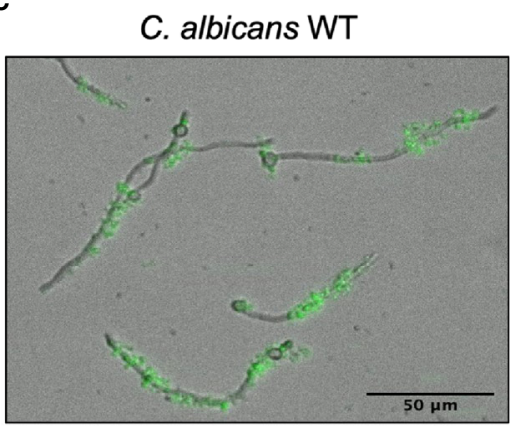

C. albicans als $3 \Delta / \Delta$

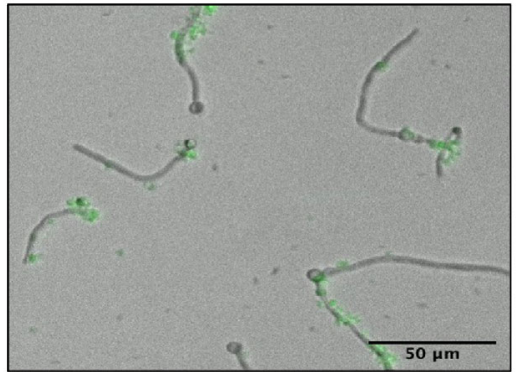

B

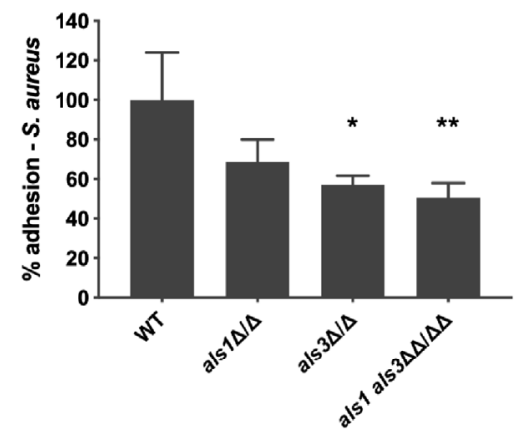

C. albicans als $1 \Delta / \Delta$

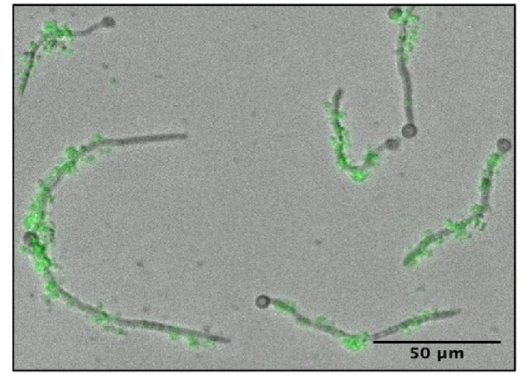

C. albicans als1 als3 $\Delta \Delta / \Delta \Delta$

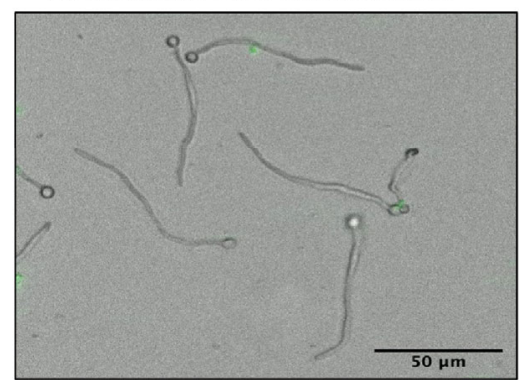

FIGURE $1 \mid$ C. albicans Als3 and Als1 adhesins are responsible for the interaction with S. aureus. Relative percentage of adhesion of the $C$. albicans deletion strains (A) and S. aureus (B) in an in vitro mixed species static adhesion assay compared to the C. albicans wild type. Statistical analysis was conducted using one-way analysis of variance (ANOVA) with Bonferroni correction ( ${ }^{*} \mathrm{P}<0.05$ and $\left.{ }^{\star \star} \mathrm{P}<0.01\right)$. (C) Visual representations of GFP-labeled $\mathrm{S}$. aureus adhesion to growing hyphae of the different $C$. albicans strains in an in vitro dynamic adhesion assay using a Bioflux system.

(Figure 3B). Gram-stained tissue sections showed the presence of $S$. aureus within the epithelium when co-infected with C. albicans wild type, however, the presence of $S$. aureus was less obvious for the $C$. albicans als1 als3 strain (Figure 3B). There were no significant differences in fungal recovery between the strains (Figure 4A). Significantly less $S$. aureus was recovered from the tongues of the animals only infected with $S$. aureus compared to those co-infected with $C$. albicans (Figure 4B). There was no difference in bacterial load recovered from the tongues of mice co-infected with the $C$. albicans als1 strain, however, a significant reduction was observed for the C. albicans als 3 and als 1 als 3 strains compared to the wild type (Figure $4 \mathbf{B}$ ). In $75 \%$ of the animals, S. aureus was able to disseminate to the kidneys when co-infected with the C. albicans wild type or als1 strain (Figure 4C). Bacterial dissemination was reduced to $50 \%$ of the cases when co-infected with the C. albicans als3 strain and no dissemination was observed when co-infected with the C. albicans als1 als3 strain. There was also no bacterial dissemination in animals only infected with $S$. aureus. Although loss of both Als1 and Als3 has a profound effect on the dissemination of $S$. aureus, this is less clear for the presence of $S$. aureus on the tongue as there is no statistical difference between the als 3 and als 1 als 3 strain. We observed dissemination of $C$. albicans to the kidneys in some animals of all groups. There was no significant difference between the $C$. albicans wild type or the different deletions strains (Figure 4D). These findings indicate that C. albicans Als1 and Als3 adhesins are crucial for $S$. aureus to disseminate.

\section{Bacterial Dissemination Depends on the Level of Immunosuppression}

To investigate a possible role for the host immune response in bacterial dissemination after C. albicans colonization, we examined the effect of the immunosuppression in the oral co-infection model. 

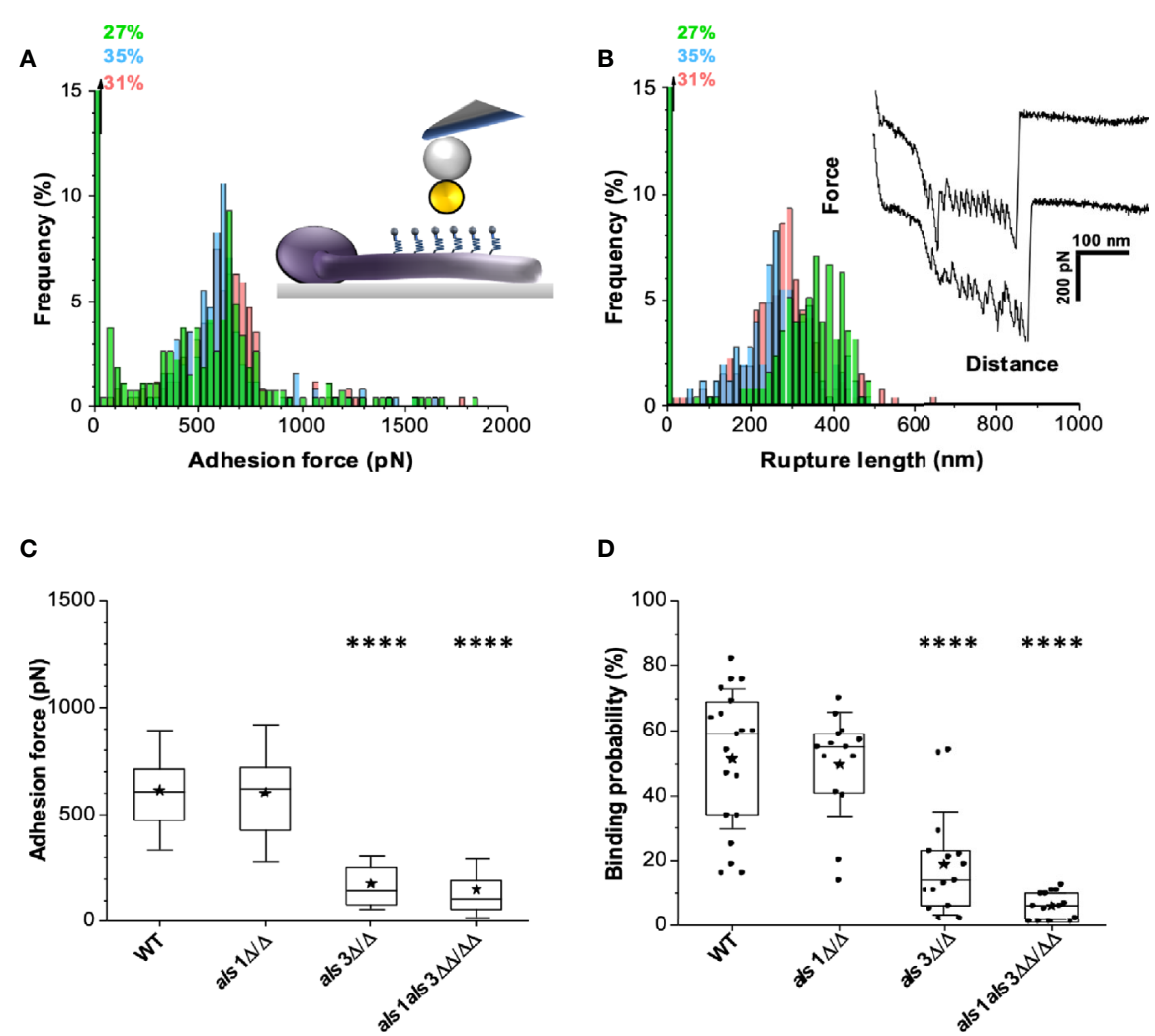

FIGURE 2 | Deletion of ALS3 and ALS1 reduces the adhesion force between C. albicans and S. aureus. (A) Adhesion force histograms (Inset: schematic representation of the experiment.) and (B) rupture length histograms with representative retraction force profiles (inset) obtained by recording force-distance curves between $S$. aureus and C. albicans wild type. Adhesion force (C) and adhesion frequency (D) for single-cell force spectroscopy experiments obtained by probing the interaction between multiple pairs of $S$. aureus-C. albicans cells. Stars are the mean values, lines are the medians and boxes the $25-75 \%$ quartiles. Statistical analysis was conducted using

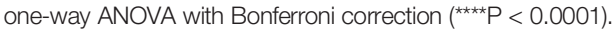

Administration of cortisone is critical for C. albicans colonization of the oral cavity since mice which are not immunosuppressed will not develop OPC (Solis and Filler, 2012). To optimize the immunosuppression level for the in vivo co-infection experiments, we comparatively tested the following concentrations of cortisone: two injections of $225 \mathrm{mg} / \mathrm{kg}$ bodyweight (low dosage) and three injections of $250 \mathrm{mg} / \mathrm{kg}$ bodyweight (high dosage). The high dosage of immunosuppression resulted in more severe lesions on the tongues caused by $C$. albicans. Consistently, a higher fungal burden was recovered from the tongues of infected mice that were immunosuppressed with the higher dosage (Figure 5A). Slightly, yet not significantly, higher levels of $S$. aureus were recovered from mice treated with the higher cortisone dosage (Figure 5B). Interestingly, we observed significantly less dissemination of $S$. aureus to the kidneys when mice were administered the high dosage of immunosuppression (Figure 5C), indicating that high levels of immunosuppression inhibit bacterial dissemination. In addition, we observed that cortisone treated mice have significantly smaller spleens and cervical lymph nodes, possibly due to severe immune cell depletion (Supplementary Figures 5A, B). To confirm these speculations, whole blood samples from healthy control mice or mice treated with a low or high cortisone dosage were analyzed. Results demonstrated a significant decrease in total white blood cells in immunocompromised mice, supporting a severe cell depletion (Figure 5D). Additionally, a decrease in number of blood lymphocytes and increase in neutrophils proportional to cortisone dosage were observed (Figure 5E). These results strongly support that the host immune response plays a crucial role in the mechanism of $S$. aureus dissemination.

\section{C. albicans Als1 and Als3 Adhesins Ensure Bacterial Uptake by Phagocytic Immune Cells}

Findings so far identified two requirements for C. albicansmediated bacterial dissemination. Firstly, adhesion of $S$. aureus to $C$. albicans mediated by both Als1 and Als3 adhesins and secondly, the host immune response. As there is a possible role for host phagocytic immune cells in this process, using the murine co-infection model, we determined the CFU of $S$. aureus in the cervical lymph nodes which drain from the oral cavity (Allison et al., 2019). No viable S. aureus was retrieved from the lymph nodes when infected with the als 1 als 3 mutant strain whereas this was the case for all other strains, indicating that Als1 and Als3 are required for S. aureus to be transported from the tongues to the lymph nodes, possible by phagocytic 
A

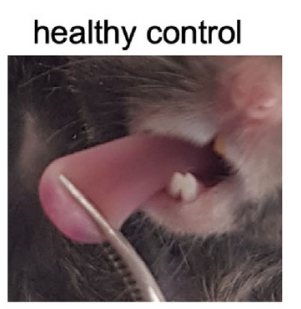

B

C. albicans WT
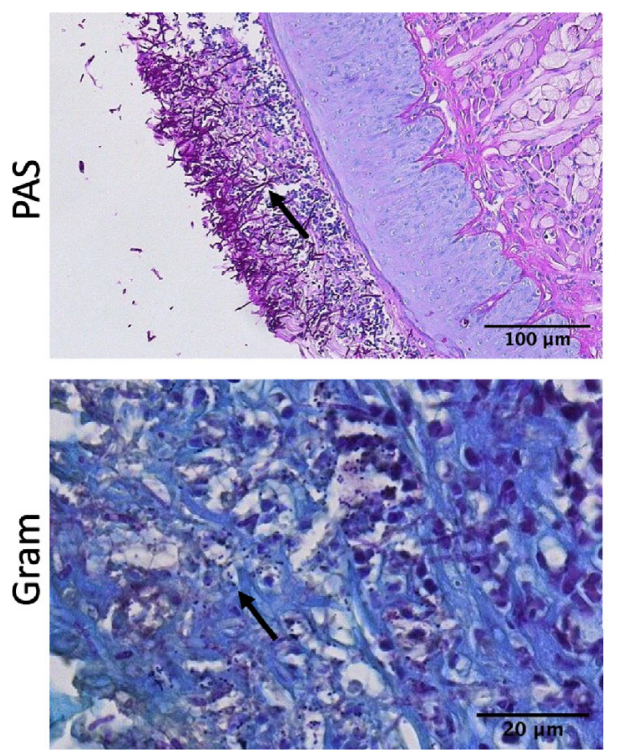

\section{C. albicans WT}

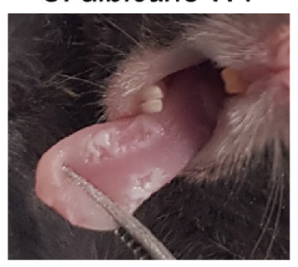

C. albicans

als1 als3 $\Delta \Delta / \Delta \Delta$

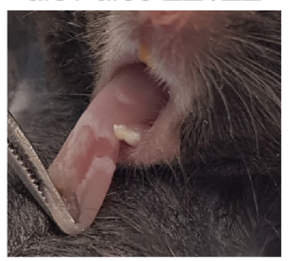

C. albicans

als1 als3 $\Delta \Delta / \Delta \Delta$
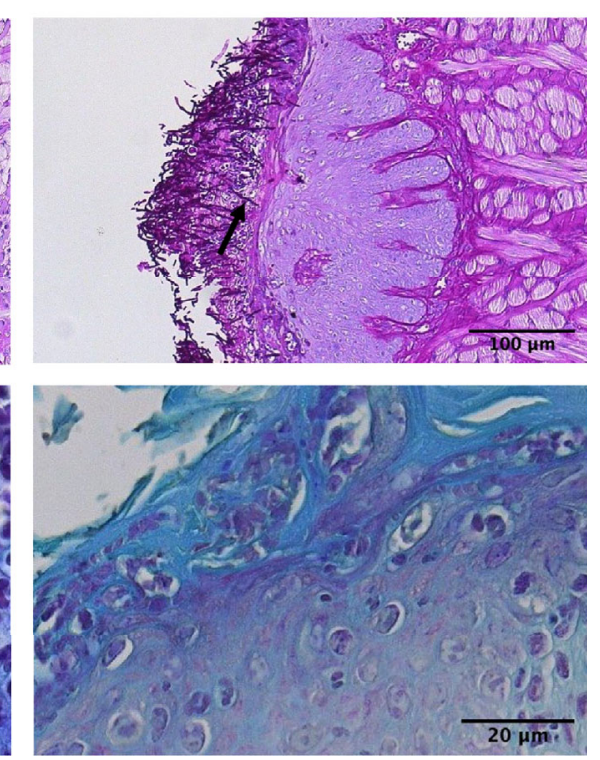

FIGURE 3 | Mouse tongue co-infection images. (A) Clinical representation of $C$. albicans infection on the mouse tongues. A healthy control tongue and tongues of mice infected with C. albicans wild type and C. albicans als1 als3 are shown. (B) Histopathology images of mice tongue tissue sections stained by PAS or Gram staining. Mice were co-infected with C. albicans wild type or als1 als3 strain. Arrows indicate invasive C. albicans hyphae for the PAS-stained images and the presence of $S$. aureus on Gram-stained images.

immune cells (Figure 6A). To elucidate why C. albicans Als1 and Als3 are required in this process, we performed in vitro phagocytosis assays with mixed $C$. albicans - S. aureus cultures. C. albicans cells were statically incubated to allow initial attachment and hyphae formation, then GFP-expressing $S$. aureus cells were added to allow bacterial attachment. Following incubation, murine macrophages were added and phagocytosis was visualized immediately. A control with no $C$. albicans cells included, demonstrated that macrophages cultured with $S$. aureus, efficiently engulf the surrounding bacteria (Figures 6B, C). When macrophages were co-cultured with $C$. albicans, they were highly attracted toward the C. albicans hyphae and importantly, they preferentially engulfed the bacteria attached to the $C$. albicans hyphae. Since bacterial attachment is strongly impaired for the C. albicans als 1 als 3 mutant strain, we show that significantly fewer macrophages were phagocytosing $S$. aureus cells when co-cultured with the $C$. albicans als 1 als 3 strain compared to the wild type strain (Figures 6B, C). As a control, we calculated the mean fluorescence intensity in each image and observed no significant difference in the amount of fluorescent $S$. aureus present (Supplementary Figure 6A). In addition, we confirmed that macrophage attraction was not impaired for the C. albicans als 1 als 3 strain compared to the wild type (Supplementary Figure 6B). These results suggest that $S$. aureus adherence to C. albicans hyphae via Als1 and Als3 adhesins increases phagocytosis of $S$. aureus by macrophages and thereby provides an opportunity for dissemination. However, it is important to note that in the in vivo situation, fewer bacteria are present when co-infected with the als 1 als 3 strain which could explain the reduction in S. aureus in the lymph nodes independently from phagocytosis by macrophages.

\section{Bacterial Dissemination Depends on the Secretion of Candidalysin}

To confirm that activation of the host immune response plays a role in the mechanism of $S$. aureus dissemination, we studied the involvement of candidalysin. Candidalysin is the best-known $C$. 

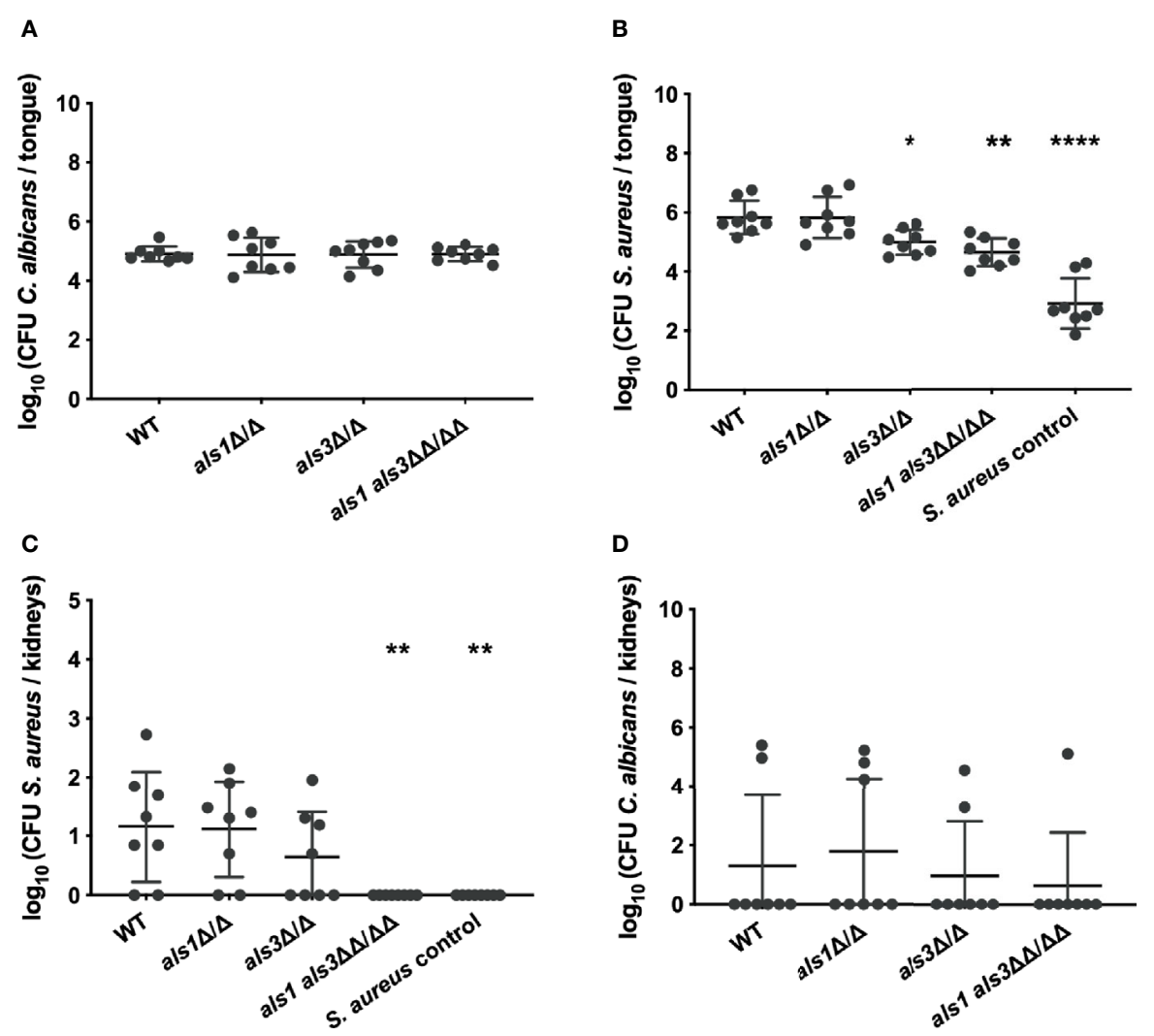

FIGURE 4 | C. albicans Als3 and Als1 are crucial for bacterial dissemination. CFU of C. albicans (A) or S. aureus (B) retrieved from the tongues of co-infected mice. CFU of C. albicans (C) or S. aureus (D) retrieved from the kidneys of mice co-infected with the different C. albicans strains. A control is shown for mice only infected

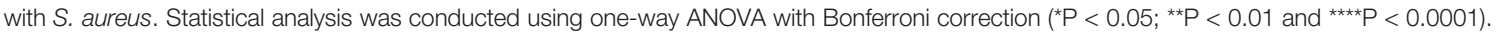

albicans peptide responsible for activation of the immune response and immune cell recruitment (Naglik et al., 2019). It is one of the eight peptides which are produced after processing of the Ece1 protein. Therefore, we generated the C. albicans ECE1 deletion strain (further referred to as ecel strain) in the SC5314 background. Since it has been reported that candidalysin is also involved in cell damage (Moyes et al., 2016), we tested the ece1 strain for cell damage to mammalian cells in vitro. As expected, we observed significantly less damage caused by the ecel strain compared to the wild type (Figure 7A). Consistent with these findings, when the ece1 strain was tested in the co-infection mouse model, only small oral lesions were seen 5 days after infection with the C. albicans ecel strain, indicating that the infection is less severe compared to animals infected with the wild type strain. A significantly smaller fungal load (Figure 7B) and significantly less S. aureus (Figure 7C) were recovered from the tongues of animals infected with the C. albicans ece 1 deletion strain. Furthermore, bacterial dissemination was observed in only one animal when co-infected with the C. albicans ece1 strain (Figure 7D). Interestingly, in vitro adhesion assays between $S$. aureus and the C. albicans ecel strain showed no significant difference in the capacity of $S$. aureus to adhere to the ecel deletion strain compared to the wild type strain (Supplementary Figures 7A, B). Combined, these findings demonstrate that Ecel is required for C. albicans colonization, immune activation and subsequent bacterial dissemination.

\section{DISCUSSION}

Polymicrobial interactions within biofilm-associated infections can enhance the virulence of the pathogens and thereby greatly influence the outcome of these infections (Harriott and Noverr, 2011; Carolus et al., 2019). Although C. albicans and S. aureus are normal commensals of most healthy humans, they are also opportunistic pathogens. We previously showed that oral infection with $C$. albicans predisposes for a secondary systemic infection of S. aureus in mice (Kong et al., 2015). In this study, we unraveled the host and pathogen mechanisms mediating bacterial dissemination. In conclusion, we show that there are two prerequisites for bacterial dissemination to occur: attachment of S. aureus to C. albicans Als1 and Als3 adhesins and the host immune response. 

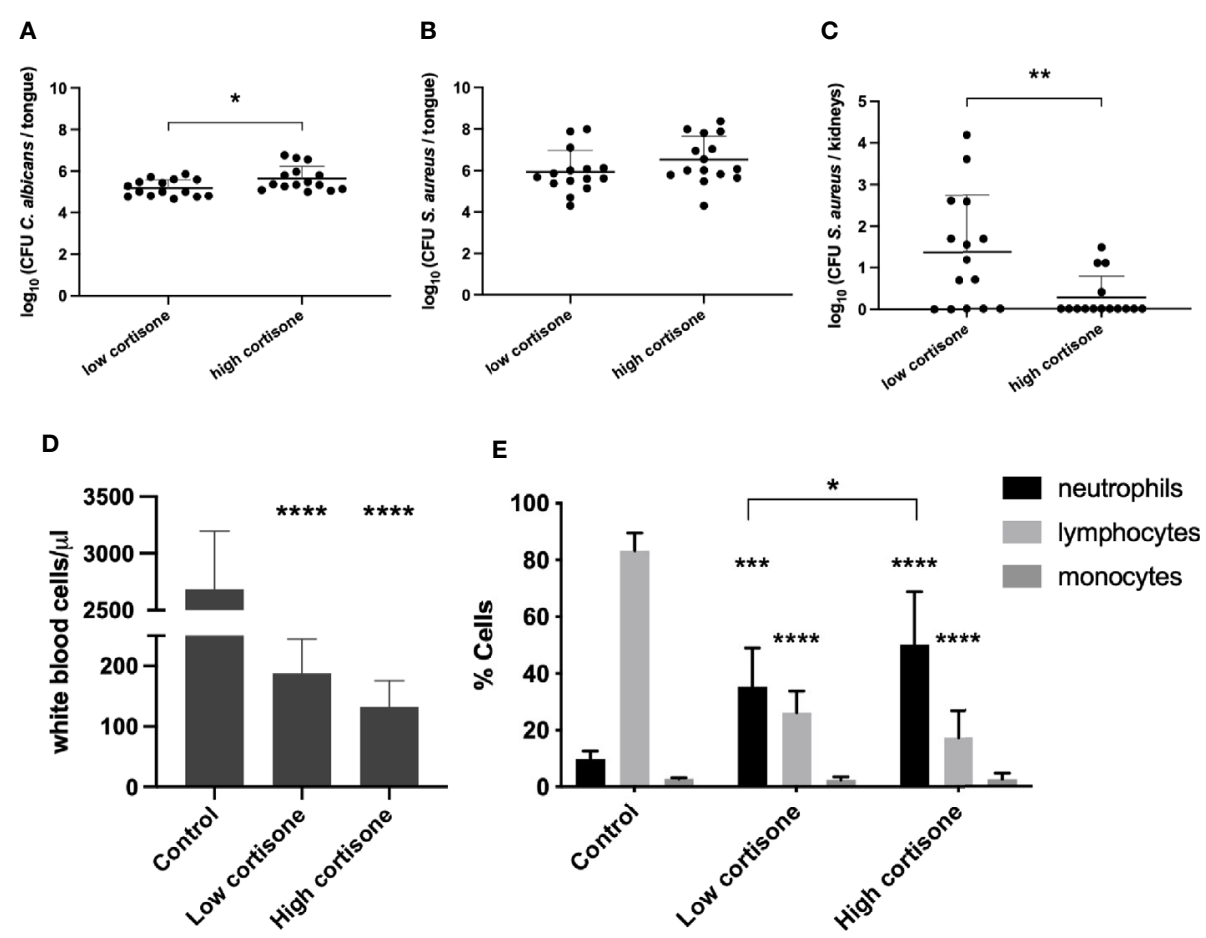

FIGURE 5 | Effect of immunosuppression in an in vivo oral co-infection mouse model. CFU of C. albicans (A) and S. aureus (B) retrieved from the tongues of mice treated with a low or high cortisone dosage. (C) CFU of $S$. aureus retrieved from the kidneys of mice treated with a low or high cortisone dosage. Statistical analysis was conducted using an unpaired Student's t-test $\left({ }^{*} P<0.05\right.$ and $\left.{ }^{* *} P<0.01\right)$. (D) The total white blood cells measured in the whole blood. Statistical analysis was conducted using one-way ANOVA with Bonferroni correction. (E) Percentages of lymphocytes, monocytes and neutrophils from the total white blood cells measured in the whole blood from control mice or mice treated with a low or high cortisone dosage. Statistical analysis was conducted using two-way ANOVA with Bonferroni correction $\left({ }^{*} \mathrm{P}<0.05 ;{ }^{* \star *} \mathrm{P}<0.001\right.$ and $\left.{ }^{\star \star \star *} \mathrm{P}<0.0001\right)$.

The C. albicans Als3 adhesin was known to partially mediate the interaction with $S$. aureus and was shown to be important in the oral co-infection model yet the additional molecules which contribute to this interaction were not yet identified (Peters et al., 2012b; Schlecht et al., 2015). We have previously shown that Als3 as well as Als1 contribute to the interaction of $C$. albicans with Staphylococcus epidermidis and the involvement in the interaction with Streptococcus gordonii was shown by others (Beaussart et al., 2013; Hoyer et al., 2014). By deleting these two proteins in this study, we show that the physical interaction with $S$. aureus is further reduced, demonstrating that in addition to Als3, Als1 contributes to the co-adherence of these species. However, there was no significant reduction in S. aureus presence on the tongue when infected with the als1 als 3 strain, compared to the als 3 single deletion strain. Importantly, deletion of both adhesins completely prevented bacterial dissemination in the oral co-infection mouse model, while this was not the case for the als 3 strain, supporting the idea that the presence of both adhesins is crucial for $S$. aureus dissemination.

Remarkably, the level of immunosuppression appeared to play an important role in the mechanism of bacterial dissemination. We found that a certain level of immunosuppression is necessary for the development of oral candidiasis, however, strongly immunosuppressed mice showed less dissemination of $S$. aureus. In mice treated with cortisone, severe cell depletion and an increased release of neutrophils in the blood were observed. This is called neutrophilia, which is also known to be accompanied with a decrease in migration of neutrophils to tissues (Ronchetti et al., 2018). In addition, cortisone acetate reduces the production of monocytes, such as macrophages, in the spleen and thereby indirectly prevents accumulation of these immune cells at infected tissue sites. Interestingly, when a range of cortisone dosages was tested, it was shown that lower dosages only delayed the development of immunity by inhibiting cell proliferation in the spleen. However, the higher dosages, completely inhibited infectioninduced spleen cell-proliferation and thereby severely suppressing immunity (North, 1971). In this regard, we hypothesize that the low cortisone dosage only delays cell-mediated immunity and allows development of OPC, however, phagocytic immune cells will still engulf $S$. aureus, which gives an opportunity for $S$. aureus to disseminate. S. aureus was shown to be able to survive phagocytosis by macrophages and neutrophils (Singh, 2017; 
A

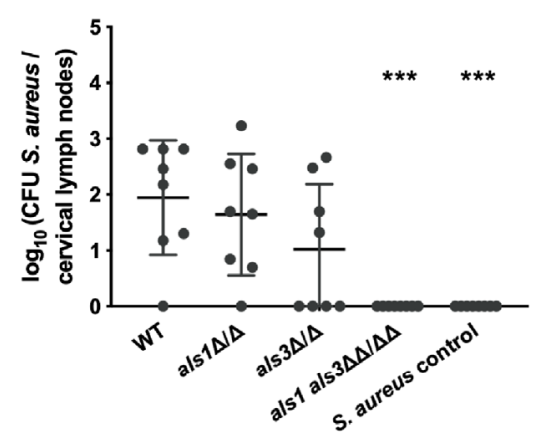

C

\section{S. aureus}
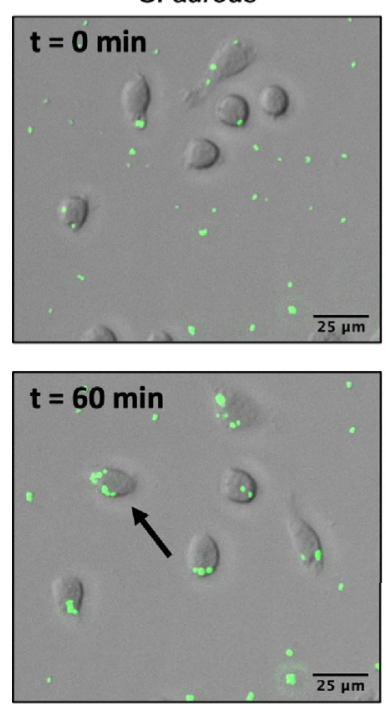

C. albicans WT $+S$. aureus
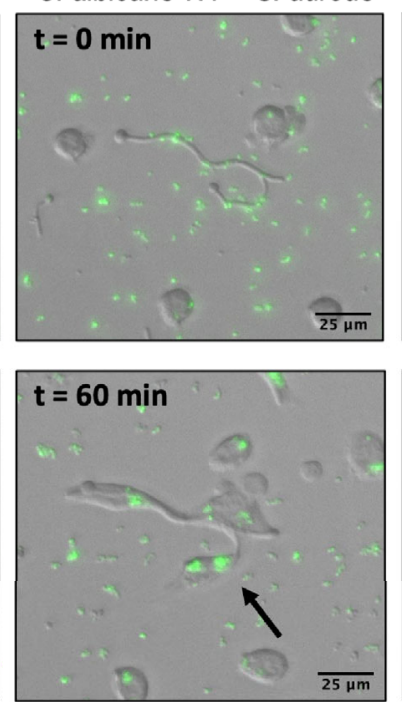

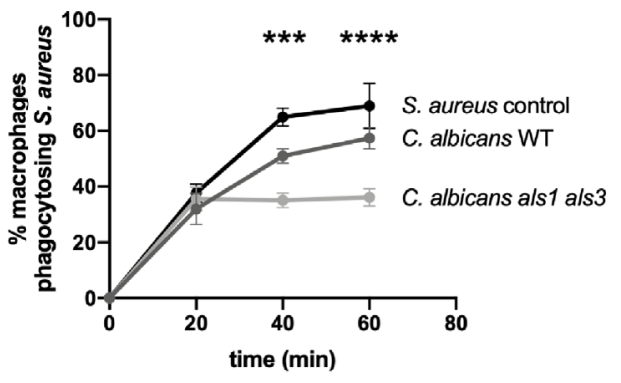

C. albicans als1 als3 $\Delta \Delta / \Delta \Delta+$ S. aureus
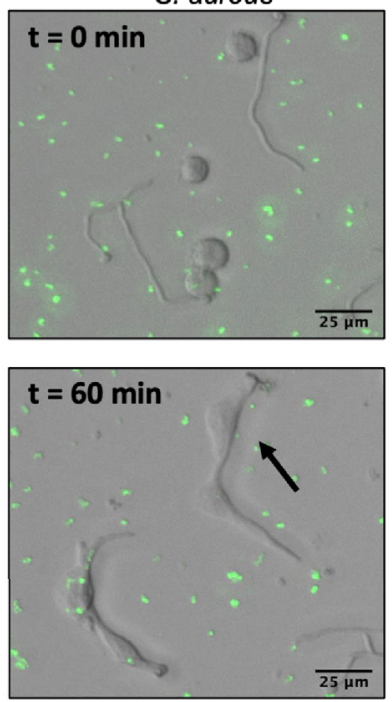

FIGURE 6 | The interaction with C. albicans ensures bacterial uptake by phagocytic immune cells. (A) CFU of S. aureus retrieved from the cervical lymph nodes of mice co-infected with the different C. albicans strains. (B) Percentage of macrophages phagocytosing S. aureus after 0, 20, 40 and 60 min of phagocytosis. Statistical analysis was conducted using two-way ANOVA with Bonferroni correction ${ }^{* \star \star} P<0.001$ and $\left.{ }^{* \star * \star P}<0.0001\right)$. (C) Visual representations are shown of the phagocytosis assays of GFP-labeled S. aureus alone or in combination with the C. albicans wild type and als 1 als 3 strain at 0 and 60 min after addition of macrophages. Arrows indicate the uptake of bacteria inside macrophages.

Moldovan and Fraunholz, 2019). In addition, we show that the physical interaction with C. albicans Als1 and Als3 enhances bacterial uptake by host phagocytic immune cells, thereby linking the requirement of the physical interaction with the importance of the immune response. It is important to note that this is a simplification of the in vivo situation in which a wide variety of immune cells and other host factors are present. Further research should focus on the investigation of this process in the in vivo mouse model using non-invasive imaging techniques.

Recently, it was shown that during mucosal C. albicans infections, candidalysin, a cytolytic peptide secreted by the hyphal form during invasion, triggers a protective immune response by the host. After recognition of the peptide, epithelial signaling is triggered which initiates neutrophil recruitment and induces maturation of primary macrophages. In addition, candidalysin mediates host cell damage and is thereby important in mucosal infections (Moyes et al., 2016; Naglik et al., 2019; Rogiers et al., 2019). Our data show that Ece1, the protein from which candidalysin is produced, is required for S. aureus dissemination. However, Ecel is processed to eight different peptides indicating that the effect is not certainly due to absence of the candidalysin peptide. In addition, it remains questionable whether the absence of bacterial dissemination is due to the lack of immune activation or the reduced colonization. Importantly, there is a reduction in S. aureus dissemination for the C. albicans als 1 als 3 deletion strain, however this strain still secretes candidalysin. Similarly, there is a reduction in S. aureus dissemination for the ece1 deletion strain, although there is no 
A

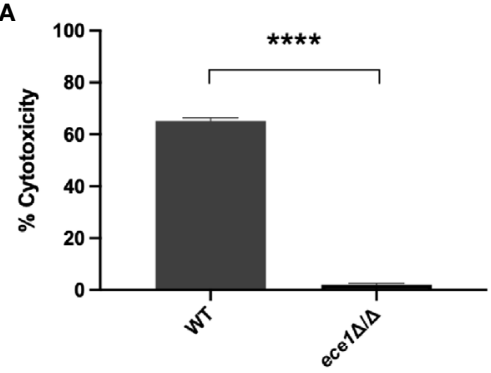

C

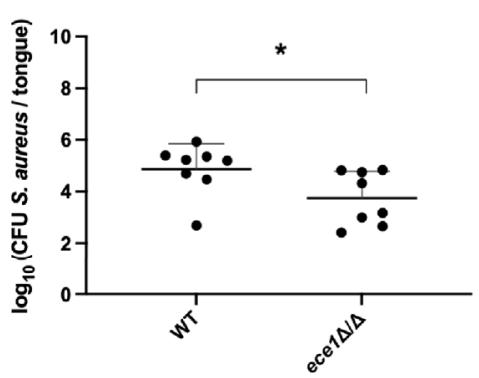

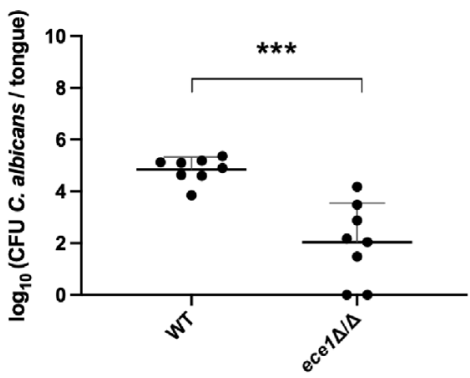

D

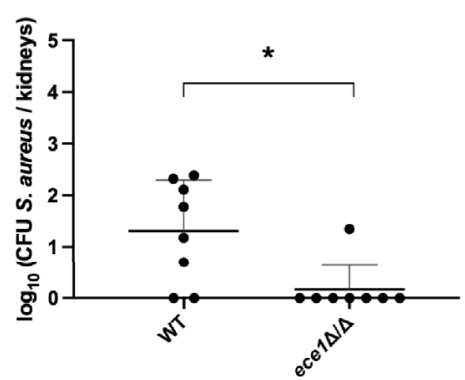

FIGURE 7 | The role of C. albicans ECE1 in an in vivo oral co-infection mouse model. (A) Percentage of cytotoxicity to mammalian cells caused by the C. albicans wild type or ece1 strain. CFU of C. albicans (B) and S. aureus (C) retrieved from the tongues of mice infected with the C. albicans wild type or ece1 strain. (D) CFU of $S$. aureus retrieved from the kidneys of mice infected with the C. albicans wild type or ece1 strain. Statistical analysis was conducted using an unpaired Student's t-test $\left({ }^{\star} P<0.05 ;{ }^{\star \star *} P<0.001\right.$ and $\left.{ }^{\star \star \star \star} P<0.0001\right)$.

adhesion defect of $S$. aureus. This might indicate that these are two independent steps in the process of bacterial dissemination which are both required.

In conclusion, based on our findings, C. albicans Als3 and Als1 could be considered as potential interesting targets in the development of treatment strategies for polymicrobial infections. Interesting $S$. aureus associated-factors mediating the interaction with C. albicans were investigated previously (Schlecht et al., 2015). S. aureus fibronectin binding protein B (FnpB), a putative surface anchored protein (SasF) and a putative $\mathrm{N}$ acetylmuramoyl-L-alanine amidase (Atl) were found to play a role in binding to $C$. albicans hyphae. Further research should focus on how these factors possibly bind C. albicans Als3 and Als1 and whether they are important for $S$. aureus dissemination. In addition, a possible role for candidalysin in mediating interspecies interactions will be of interest in further research. These findings highlight the complexity of interactions between pathogens and the host in polymicrobial infections, and identify a potential paradoxical role for immunosuppression in a clinical setting.

\section{DATA AVAILABILITY STATEMENT}

The original contributions presented in the study are included in the article/Supplementary Material. Further inquiries can be directed to the corresponding author.

\section{ETHICS STATEMENT}

The animal study was reviewed and approved by Ethics Committee on animal experimentation of the KU Leuven (project number P184/2017).

\section{AUTHOR CONTRIBUTIONS}

Conceptualization: KV, MJ-R, GV, YD, BK, and PV. Methodology and investigation: KV, FV, MM-G, and LD. Formal analysis: KV, FV, MM-G, and EH. Writing (original draft): KV. Writing (review and editing): all authors. Funding acquisition: MJ-R, YD, and PV. Resources, YD, BK, and PV. Supervision: MJ-R, GV, YD, BK, and $\mathrm{PV}$. All authors contributed to the article and approved the submitted version.

\section{FUNDING}

KV was supported by a personal research grant $(1181818 \mathrm{~N})$ from the Fund for Scientific Research Flanders (FWO). This work was supported by the FWO research community on biofilms (W000921N) and by the National Institute of Allergy and Infectious Diseases of the NIH under award number R01AI130170 (NIAID) to MJ-R. Work at the Universite Catholique de Louvain was supported by the National Fund for Scientific Research (FNRS) and the Research Department of the Communauté Française de Belgique (Concerted Research Action). YD is a Research Director at the FNRS. 


\section{ACKNOWLEDGMENTS}

We thank Saleh Yazdani and Selien Schots for technical assistance. All authors contributed to discussion of the results. This work is dedicated to the memory of Mark E. Shirtliff.

\section{REFERENCES}

Allison, D. L., Scheres, N., Willems, H. M. E., Bode, C. S., Krom, B. P., and Shirtliff, M. E. (2019). The Host Immune System Facilitates Disseminated Staphylococcus aureus Disease Due to Phagocytic Attraction to Candida albicans during Coinfection: a Case of Bait and Switch. Infect. Immun. 87 (11), e00137-19. doi: 10.1128/IAI.00137-19

Beaussart, A., Herman, P., El-Kirat-Chatel, S., Lipke, P. N., Kucharikova, S., Van Dijck, P., et al. (2013). Single-cell force spectroscopy of the medically important Staphylococcus epidermidis-Candida albicans interaction. Nanoscale 5, 1089410900. doi: $10.1039 / \mathrm{c} 3 \mathrm{nr} 03272 \mathrm{~h}$

Beaussart, A., El-Kirat-Chatel, S., Sullan, R. M., Alsteens, D., Herman, P., Derclaye, S., et al. (2014). Quantifying the forces guiding microbial cell adhesion using single-cell force spectroscopy. Nat. Protoc. 9, 1049-1055. doi: 10.1038/nprot.2014.066

Berman, J. (2012). Candida albicans. Curr. Biol. 22, R620-R622. doi: 10.1016/ j.cub.2012.05.043

Carlson, E. (1982). Synergistic effect of Candida albicans and Staphylococcus aureus on mouse mortality. Infect. Immun. 38, 921-924. doi: 10.1128/ IAI.38.3.921-924.1982

Carlson, E. (1983). Effect of strain of Staphylococcus aureus on synergism with Candida albicans resulting in mouse mortality and morbidity. Infect. Immun. 42, 285-292. doi: 10.1128/IAI.42.1.285-292.1983

Carolus, H., Van Dyck, K., and Van Dijck, P. (2019). Candida albicans and Staphylococcus Species: A Threatening Twosome. Front. Microbiol. 10, 2162. doi: $10.3389 /$ fmicb.2019.02162

David, M. Z., and Daum, R. S. (2010). Community-associated methicillin-resistant Staphylococcus aureus: epidemiology and clinical consequences of an emerging epidemic. Clin. Microbiol. Rev. 23, 616-687. doi: 10.1128/CMR.00081-09

Deleo, F. R., Otto, M., Kreiswirth, B. N., and Chambers, H. F. (2010). Communityassociated meticillin-resistant Staphylococcus aureus. Lancet 375, 1557-1568. doi: 10.1016/S0140-6736(09)61999-1

Fanning, S., Xu, W., Solis, N., Woolford, C. A., Filler, S. G., and Mitchell, A. P. (2012). Divergent targets of Candida albicans biofilm regulator Bcr1 in vitro and in vivo. Eukaryot. Cell 11, 896-904. doi: 10.1128/EC.00103-12

Gillum, A. M., Tsay, E. Y., and Kirsch, D. R. (1984). Isolation of the Candida albicans gene for orotidine-5'-phosphate decarboxylase by complementation of S. cerevisiae ura3 and E. coli pyrF mutations. Mol. Gen. Genet. 198, 179-182. doi: 10.1007/BF00328721

Harriott, M. M., and Noverr, M. C. (2011). Importance of Candida-bacterial polymicrobial biofilms in disease. Trends Microbiol. 19, 557-563. doi: 10.1016/ j.tim.2011.07.004

Ho, V., Herman-Bausier, P., Shaw, C., Conrad, K. A., Garcia-Sherman, M. C., Draghi, J., et al. (2019). An Amyloid Core Sequence in the Major Candida albicans Adhesin Als1p Mediates Cell-Cell Adhesion. mBio 10 (5), e01766-19. doi: $10.1128 / \mathrm{mBio} .01766-19$

Hoyer, L. L., and Cota, E. (2016). Candida albicans Agglutinin-Like Sequence (Als) Family Vignettes: A Review of Als Protein Structure and Function. Front. Microbiol. 7, 280. doi: 10.3389/fmicb.2016.00280

Hoyer, L. L., Payne, T. L., Bell, M., Myers, A. M., and Scherer, S. (1998). Candida albicans ALS3 and insights into the nature of the ALS gene family. Curr. Genet. 33, 451-459. doi: 10.1007/s002940050359

Hoyer, L. L., Green, C. B., Oh, S. H., and Zhao, X. (2008). Discovering the secrets of the Candida albicans agglutinin-like sequence (ALS) gene family-a sticky pursuit. Med. Mycol. 46, 1-15. doi: 10.1080/13693780701435317

Hoyer, L. L., Oh, S. H., Jones, R., and Cota, E. (2014). A proposed mechanism for the interaction between the Candida albicans Als3 adhesin and streptococcal cell wall proteins. Front. Microbiol. 5, 564. doi: 10.3389/fmicb.2014.00564

Kong, E., and Jabra-Rizk, M. A. (2015). The great escape: pathogen versus host. PloS Pathog. 11, e1004661. doi: 10.1371/journal.ppat.1004661

Kong, E. F., Kucharikova, S., Van Dijck, P., Peters, B. M., Shirtliff, M. E., and JabraRizk, M. A. (2015). Clinical implications of oral candidiasis: host tissue damage

\section{SUPPLEMENTARY MATERIAL}

The Supplementary Material for this article can be found online at: https://www.frontiersin.org/articles/10.3389/fcimb.2020. 624839/full\#supplementary-material

and disseminated bacterial disease. Infect. Immun. 83, 604-613. doi: 10.1128/ IAI.02843-14

Kong, E. F., Johnson, J. K., and Jabra-Rizk, M. A. (2016). Community-Associated Methicillin-Resistant Staphylococcus aureus: An Enemy amidst Us. PloS Pathog. 12, e1005837. doi: 10.1371/journal.ppat.1005837

Li, J., Busscher, H. J., Van Der Mei, H. C., Norde, W., Krom, B. P., and Sjollema, J. (2011). Analysis of the contribution of sedimentation to bacterial mass transport in a parallel plate flow chamber: part II: use of fluorescence imaging. Colloids Surf. B Biointerf. 87, 427-432. doi: 10.1016/j.colsurfb.2011.06.002

Liu, Y., and Filler, S. G. (2011). Candida albicans Als3, a multifunctional adhesin and invasin. Eukaryot. Cell 10, 168-173. doi: 10.1128/EC.00279-10

Lohse, M. B., Gulati, M., Johnson, A. D., and Nobile, C. J. (2018). Development and regulation of single- and multi-species Candida albicans biofilms. Nat. Rev. Microbiol. 16, 19-31. doi: 10.1038/nrmicro.2017.107

Mayer, F. L., Wilson, D., and Hube, B. (2013). Candida albicans pathogenicity mechanisms. Virulence 4, 119-128. doi: 10.4161/viru.22913

Mccormack, M. G., Smith, A. J., Akram, A. N., Jackson, M., Robertson, D., and Edwards, G. (2015). Staphylococcus aureus and the oral cavity: an overlooked source of carriage and infection? Am. J. Infect. Control 43, 35-37. doi: 10.1016/ j.ajic.2014.09.015

Moldovan, A., and Fraunholz, M. J. (2019). In or out: Phagosomal escape of Staphylococcus aureus. Cell Microbiol. 21, e12997. doi: 10.1111/cmi.12997

Montelongo-Jauregui, D., and Lopez-Ribot, J. L. (2018). Candida Interactions with the Oral Bacterial Microbiota. J. Fungi (Basel) 4 (4), 122. doi: 10.3390/jof 4040122

Moyes, D. L., Wilson, D., Richardson, J. P., Mogavero, S., Tang, S. X., Wernecke, J., et al. (2016). Candidalysin is a fungal peptide toxin critical for mucosal infection. Nature 532, 64-68. doi: 10.1038/nature17625

Mukaremera, L., Lee, K. K., Mora-Montes, H. M., and Gow, N. A. R. (2017). Candida albicans Yeast, Pseudohyphal, and Hyphal Morphogenesis Differentially Affects Immune Recognition. Front. Immunol. 8, 629. doi: 10.3389/fimmu.2017.00629

Naglik, J. R., Gaffen, S. L., and Hube, B. (2019). Candidalysin: discovery and function in Candida albicans infections. Curr. Opin. Microbiol. 52, 100-109. doi: 10.1016/j.mib.2019.06.002

Nieto, C., and Espinosa, M. (2003). Construction of the mobilizable plasmid pMV158GFP, a derivative of pMV158 that carries the gene encoding the green fluorescent protein. Plasmid 49, 281-285. doi: 10.1016/S0147-619X(03)00020-9

Nobile, C. J., Andes, D. R., Nett, J. E., Smith, F. J., Yue, F., Phan, Q. T., et al. (2006). Critical role of Bcrl-dependent adhesins in C. albicans biofilm formation in vitro and in vivo. PloS Pathog. 2, e63. doi: 10.1371/journal.ppat.0020063

North, R. J. (1971). The action of cortisone acetate on cell-mediated immunity to infection. Suppression of host cell proliferation and alteration of cellular composition of infective foci. J. Exp. Med. 134, 1485-1500. doi: 10.1084/jem.134.6.1485

Patil, S., Rao, R. S., Majumdar, B., and Anil, S. (2015). Clinical Appearance of Oral Candida Infection and Therapeutic Strategies. Front. Microbiol. 6, 1391. doi: 10.3389/fmicb.2015.01391

Peters, B. M., and Noverr, M. C. (2013). Candida albicans-Staphylococcus aureus polymicrobial peritonitis modulates host innate immunity. Infect. Immun. 81, 2178-2189. doi: 10.1128/IAI.00265-13

Peters, B. M., Jabra-Rizk, M. A., O’may, G. A., Costerton, J. W., and Shirtliff, M. E. (2012a). Polymicrobial Interactions: Impact on Pathogenesis and Human Disease. Clin. Microbiol. Rev. 25, 193-19+. doi: 10.1128/CMR.00013-11

Peters, B. M., Ovchinnikova, E. S., Krom, B. P., Schlecht, L. M., Zhou, H., Hoyer, L. L., et al. (2012b). Staphylococcus aureus adherence to Candida albicans hyphae is mediated by the hyphal adhesin Als3p. Microbiology-Sgm 158, 2975-2986. doi: 10.1099/mic.0.062109-0

Rogiers, O., Frising, U. C., Kucharikova, S., Jabra-Rizk, M. A., Van Loo, G., Van Dijck, P., et al. (2019). Candidalysin Crucially Contributes to Nlrp3 Inflammasome Activation by Candida albicans Hyphae. MBio 10 (1), e02221-18. doi: 10.1128/mBio.02221-18 
Ronchetti, S., Ricci, E., Migliorati, G., Gentili, M., and Riccardi, C. (2018). How Glucocorticoids Affect the Neutrophil Life. Int. J. Mol. Sci. 19 (12), 4090. doi: 10.3390/ijms 19124090

Sasse, C., and Morschhauser, J. (2012). Gene deletion in Candida albicans wildtype strains using the SAT1-flipping strategy. Methods Mol. Biol. 845, 3-17. doi: 10.1007/978-1-61779-539-8_1

Scheres, N., and Krom, B. P. (2016). Staphylococcus-Candida Interaction Models: Antibiotic Resistance Testing and Host Interactions. Methods Mol. Biol. 1356, 153-161. doi: 10.1007/978-1-4939-3052-4_11

Schlecht, L. M., Peters, B. M., Krom, B. P., Freiberg, J. A., Hansch, G. M., Filler, S. G., et al. (2015). Systemic Staphylococcus aureus infection mediated by Candida albicans hyphal invasion of mucosal tissue. Microbiology 161, 168-181. doi: 10.1099/mic.0.083485-0

Shirtliff, M. E., Peters, B. M., and Jabra-Rizk, M. A. (2009). Cross-kingdom interactions: Candida albicans and bacteria. FEMS Microbiol. Lett. 299, 1-8. doi: 10.1111/j.1574-6968.2009.01668.x

Singh, S. K. (2017). Staphylococcus aureus intracellular survival: A closer look in the process. Virulence 8, 1506-1507. doi: 10.1080/21505594.2017.1384896

Solis, N. V., and Filler, S. G. (2012). Mouse model of oropharyngeal candidiasis. Nat. Protoc. 7, 637-642. doi: 10.1038/nprot.2012.011

Sultan, A. S., Kong, E. F., Rizk, A. M., and Jabra-Rizk, M. A. (2018). The oral microbiome: A Lesson in coexistence. PloS Pathog. 14, e1006719. doi: 10.1371/journal.ppat.1006719

Swidergall, M., and Filler, S. G. (2017). Oropharyngeal Candidiasis: Fungal Invasion and Epithelial Cell Responses. PloS Pathog. 13, e1006056. doi: 10.1371/journal.ppat.1006056

Tenover, F. C., and Goering, R. V. (2009). Methicillin-resistant Staphylococcus aureus strain USA300: origin and epidemiology. J. Antimicrob. Chemother. 64, 441-446. doi: 10.1093/jac/dkp241
Thomer, L., Schneewind, O., and Missiakas, D. (2016). Pathogenesis of Staphylococcus aureus Bloodstream Infections. Annu. Rev. Pathol. 11, 343364. doi: 10.1146/annurev-pathol-012615-044351

Van Der Mee-Marquet, N., Domelier, A. S., Girard, N., Quentin, R.Bloodstream Infection Study Group of the Relais D'hygiene Du, C. (2004). Epidemiology and typing of Staphylococcus aureus strains isolated from bloodstream infections. J. Clin. Microbiol. 42, 5650-5657. doi: 10.1128/JCM.42.12.5650-5657.2004

Vila, T., Sultan, A. S., Montelongo-Jauregui, D., and Jabra-Rizk, M. A. (2020). Oral Candidiasis: A Disease of Opportunity. J. Fungi (Basel) 6 (1), 15. doi: 10.3390/ jof6010015

Xiao, J., and Dufrene, Y. F. (2016). Optical and force nanoscopy in microbiology. Nat. Microbiol. 1, 16186. doi: 10.1038/nmicrobiol.2016.186

Zhao, X., Oh, S. H., Cheng, G., Green, C. B., Nuessen, J. A., Yeater, K., et al. (2004) ALS3 and ALS8 represent a single locus that encodes a Candida albicans adhesin; functional comparisons between Als3p and Als1p. Microbiology 150, 2415-2428. doi: 10.1099/mic.0.26943-0

Conflict of Interest: The authors declare that the research was conducted in the absence of any commercial or financial relationships that could be construed as a potential conflict of interest.

Copyright (c) 2021 Van Dyck, Viela, Mathelié-Guinlet, Demuyser, Hauben, Jabra-Rizk, Vande Velde, Dufrêne, Krom and Van Dijck. This is an open-access article distributed under the terms of the Creative Commons Attribution License (CC BY). The use, distribution or reproduction in other forums is permitted, provided the original author(s) and the copyright owner(s) are credited and that the original publication in this journal is cited, in accordance with accepted academic practice. No use, distribution or reproduction is permitted which does not comply with these terms. 